\title{
A LINEAR PROGRAMMING TECHNIQUE TO SOLVE FUZZY MULTIPLE CRITERIA DECISION MAKING PROBLEMS WITH AN APPLICATION
}

\author{
Seyed Ali Sadabadi, Abdollah Hadi-Vencheh*, Ali Jamshidi \\ AND MOHAMMAD JALALI
}

\begin{abstract}
Generally, in real world multiple criteria decision making (MCDM) problems, we concern with inaccurate data. This paper transforms a fuzzy multiple criteria decision making (FMCDM) problem into two linear programming models based on simple additive weighting method (SAW). The new linear models calculate two scores for each alternative in optimistic and pessimistic viewpoints. To rank the alternatives, the numerical value of the arithmetic mean of good score and bad score is used as final score of each alternative. Finally, we illustrate the practical applications of the proposed method in selection an industrial zone for construct dairy products factory.
\end{abstract}

Mathematics Subject Classification. 90C05, 90C70.

Received October 13, 2019. Accepted October 11, 2020.

\section{INTRODUCTION}

In classical MCDM problems, we need accurate data. However, in the real world access to accurate data is not always possible, especially when the set of alternatives includes incomplete data, vague data or predictive data. Interactive conversations, inaccurate information, or vague data can be identified by fuzzy numbers which in a special case contain interval numbers. Therefore, the evaluation of a group of alternatives that includes fuzzy performance is a matter of study $[1,30,31,34]$.

Several attempts have been made in the field of solving FMCDM [3,4,6,12, 16, 36, 38, 41, 42]. For example, Chen [6] suggests an extension of the technique for order preference by similarity to ideal solution (TOPSIS) to the fuzzy environment. In his method the rate of each alternative and the weight of criteria are described by linguistic terms. Then, a vertex method is proposed to calculate the distance between two triangular fuzzy numbers. He employs the concept of TOPSIS, to determine the ranking order of all alternatives by calculating the distance to both the fuzzy positive ideal solution (FPIS) and fuzzy negative ideal solution (FNIS) simultaneously. Jahanshahloo et al. [18] extend fuzzy TOPSIS method based on the concept of alpha-cuts of fuzzy numbers. Wang and Elhag [36] propose a fuzzy TOPSIS using alpha-level sets, in which the TOPSIS index is obtained from solving a nonlinear programming. A centroid-index ranking method of fuzzy numbers based on TOPSIS proposed by Yong and Qi [40]. Using some numerical examples authors show that their method can overcome the

Keywords. Fuzzy multiple criteria decision making (FMCDM), simple additive weighted (SAW), fuzzy TOPSIS (FTOPSIS), linear programming (LP).

Department of Mathematics, Isfahan (Khorasgan) Branch, Islamic Azad University, Isfahan, Iran.

*Corresponding author: ahadi@khuisf.ac.ir, abdh12345@yahoo.com 
drawbacks of the existing methods. To select the location of the international tourist hotel, Chou et al. [8] present a FMCDM model. They consider 21 criteria and use fuzzy analytic hierarchy process (FAHP) to consolidate decision-makers' assessments about criteria weightings. Wang et al. [37] apply an FMCDM model for selecting and evaluating trigeneration systems. Dalalah et al. [9] propose hybrid group FMCDM model and provide a modified fuzzy Decision Making Trial and Evaluation Laboratory Method (DEMATEL) model to deal with the relationships between the criteria. They modify TOPSIS model to evaluate the criteria for each alternative. A hybrid model was used in an industrial case study to select suppliers at the Nutridar factory in Oman, Jordan. Yücel and Güneri [42] examine the concept of ambiguity and fuzzy in supplier selections problem and develop a weighted fuzzy programming method. They first use the linguistic values as a trapezoidal fuzzy number to evaluate the weight of the factors. Then they obtain the weights using the distance between each factor to FPIS and the FNIS. A FMCDM approach based on centroid of fuzzy numbers was presented by Hadi-Vencheh and Mokhtarian [13]. Also, Mokhtarian and Hadi-Vencheh [27] presented a fuzzy TOPSIS method based on left and right scores. An FMCDM model for Building Energy Performance in Turkey (BEP-TR) analysis was proposed by Kabak et al. [20]. Arslan and Çunkaş [3] presented the performance evaluation of sugar plants using the TOPSIS under a fuzzy environment. Ruiz-Padillo et al. [33] suggest a multiple criteria decision methodology for the selection of suitable alternatives against traffic noise in each of the road stretches included in the noise action plans (NAPs). The methodology first defines the main criteria and alternatives to be considered. Secondly, it determines the relative weights for the criteria and sub-criteria using the fuzzy extended analytical hierarchy process. Hatami-Maribini and Kangi propose [16] an FMCDM model for stock market capitalization. They present three versions of fuzzy TOPSIS, i.e., conventional TOPSIS (C-TOPSIS), adjusted TOPSIS (A-TOPSIS) and modified TOPSIS (M-TOPSIS). Wei et al. [39] develop a method in which the criteria values take the form of the hesitant fuzzy elements (HFEs). Based on the $\lambda$-fuzzy measure, they firstly get the weight vector of the criteria. Then, a linear assignment method is proposed to acquire the optimal preference ranking of the alternatives. Beg and Rashid [4] suggest a notion for the distance between fuzzy hesitant numbers. Using this new distance notion, they propose the TOPSIS method for hesitant fuzzy sets. Naili et al. [28] employ braininspired method to solve FMCDM problems. Their methodology is based on an abstraction and a simulation of some brain's emotional processing mechanisms using the fuzzy sets theory. To prove the performance of their proposed method, they have studied a problem of websites ranking which represents an important research theme in the World Wide Wisdom Web (W4). Tavana et al. [35] proposed a fuzzy hybrid project portfolio selection method using Data Envelopment Analysis (DEA), TOPSIS and Integer Programming (IP). They propose a three-stage hybrid method for selecting an optimal combination of projects. Their model is comprised of three stages and each stage is composed of several steps and procedures. They use DEA for the initial screening, the TOPSIS for ranking the projects, and linear IP for selecting the most suitable project portfolio in a fuzzy environment according to organizational objectives. Ljubojević et al. [25] presented a hybrid methodological approach to the problem of selecting the transport service provider, based on the idea of comparing the ideal parameters and real parameters of alternative providers. Yatsalo et al. [40] proposed a approach to MCDM under fuzzy environment. In their approach the MCDM problems are defined under fuzzy contexts that implement the concept of acceptability analysis, Fuzzy Multi-Criteria Acceptability Analysis (FMAA), based on the Fuzzy Rank Acceptability Analysis (FRAA) that provides a ranking and a confidence degree about the ranking of fuzzy quantities. Arroyo-Canada and Gil-Lafuente [2] proposed a TOPSIS-based approach, which allows us to rank the alternative keyword sets, taking into account the fuzzy nature of the available data. The suitability of the proposed model is illustrated with an empirical case of a stock exchange broker's advertising investment problem aimed at generating awareness about the brand and increasing the traffic to the corporative website. Lopez et al. [26] presented web-based multi-criteria group decision support system for solving multi-criteria ranking problems by a collaborative group of DMs in sequential or parallel coordination mode and in a distributed and asynchronous environment. Han and Trimi [15] proposed a fuzzy TOPSIS method for performance evaluation of reverse logistics in social commerce platforms. They identify the criteria that should be used in designing and evaluating social commerce based reverse logistics processes by firms. First, they identify the criteria from a thorough review of the literature. Then, they invite five experts to provide (linguistic) ratings of these firms on 
the selected criteria, using a fuzzy TOPSIS with FLINTSTONES (a software tool) to generate aggregate scores for the assessment and evaluation of reverse logistics practices in social commerce platforms. Dwivedi et al. [11] propose a Generalized-Fuzzy-TOPSIS method as a versatile evaluation model. They express that, their model is suitable for different types of fuzzy or interval-valued numbers, with or without subjective weights of criteria being defined by evaluators. Additionally, they extend the final ranking step of the TOPSIS method, which is the calculation of closeness coefficient based on the separation from negative ideal solution (NIS) and proximity to positive ideal solution (PIS). Joshi and Kumar [19] proposed an improved accuracy function to compare all comparable interval-valued intuitionistic fuzzy sets (IVIFSs) and apply their method on a real case study of evaluation teachers' performance.

From the above literature review we find the following issues. Most of current FMCDM are solved using defuzzification or alpha-cut strategy. It is worthy to note that in the methods which employ alpha levels the degree of accuracy depends on the number of alpha-levels and as a result to achieve accurate result the computational burden is usually high. Also, in some methods the distance between each alternative to the PIS and NIS depend on the weight of the criteria. Generally, these weights are determined by a group of experts and clearly by changing the group members, the weight of the criteria may change, and consequently the rank of alternatives may change as well.

The purpose of this paper is to propose a novel method for solving an FMCDM problem. In the proposed method, the FMCDM problem is easily formulated into two linear programming (LP) models without need to very large computational efforts. One of these two LPs is optimistic since it maximizes the score of the under evaluation alternative subjected to the constraints that the weighted sum for all the alternatives based on the same set of weights must be less or equal to one. In this way, each alternative can obtain a set of weights which are most favourable for it. Similarly, the other LP model has a pessimistic viewpoint since this LP minimizes the score of alternative such that weighted sum for all the alternatives must be greater or equal to one. Hence, each alternative get a set of weights which are least favourable. Thus, the proposed approach provides two sets of weights that are most favourable and least favourable for each alternative. Finally, the weight of criteria is obtained, and alternatives are ranked based on the optimal solution of two LPs.

The rest of this article is as follows: In the following section, some preliminaries are given. Section 3 is devoted to presented method. Then, in Section 4 the proposed method is compared with fuzzy TOPSIS along with three numerical examples. The article is concluded in last section.

\section{Preliminaries}

\subsection{Fuzzy sets}

Fuzzy sets are generalized sets of crisp and accurate sets [43]. Each fuzzy set is characterized by a membership function, so that the membership of each element of this set is determined with a membership degree in the range of $[0,1]$. If the degree of membership is zero, the desired element does not belong to the collection. If the degree of membership is equal to one, the given element is totally belongs to the set. If the degree of membership is between zero and one, only a part of the given element belongs to the set. Therefore, each fuzzy set can be singularly determined using its membership function. Suppose $X$ is the universe set to be discussed.

We call a fuzzy set $\tilde{A}$ of the reference set $X$ convex if and only if for each $x_{1}$ and $x_{2}$ in $X$ :

$$
\mu_{\tilde{A}}\left(\lambda x_{1}+(1-\lambda) x_{2}\right) \geq \operatorname{Min}\left(\mu_{\tilde{A}}\left(x_{1}\right), \mu_{\tilde{A}}\left(x_{2}\right)\right) .
$$

So that $\mu_{\tilde{A}}(x)$ is the degree of membership of the fuzzy set $\tilde{A}$ and $\lambda \in[0,1]$.

A fuzzy set $\tilde{A}$ of the reference set $X$ is said to be normal if there exists a $x_{i} \in X$ satisfying $\mu_{\tilde{A}}\left(x_{i}\right)=1$.

Fuzzy numbers are a special case of fuzzy sets, both convex and normal. A fuzzy number is a convex fuzzy set, characterized by a given interval of real numbers, each of which has a membership degree between zero and one. The membership function of the fuzzy number is piecewise continuous and satisfies the following conditions: 
(a) $\mu_{\tilde{A}}(x)=0$ for $\forall x \notin[a, d]$;

(b) $\mu_{\tilde{A}}(x)$ is non-decreasing (monotonic increasing) on $[a, b]$ and is non-increasing (monotonic decreasing) on $[c, d]$

(c) $\mu_{\tilde{A}}(x)=1$ for all $x \in[b, c]$,

where $a \leq b \leq c \leq d$ are real numbers in the real line $R=(-\infty,+\infty)$.

The well-known fuzzy number is triangular fuzzy number, whose membership function is as follows [5]:

$$
\mu_{\tilde{A}}(x)= \begin{cases}(x-a) /(b-a), & a \leq x \leq b \\ (c-x) /(c-b), & b \leq x \leq c . \\ 0, & \text { otherwise }\end{cases}
$$

Generally, a triangular fuzzy number is briefly represented by $(a, b, c)$. A triangular fuzzy number $(a, b, c)$ is said to be positive if and only if $a>0$ [21].

Two triangular fuzzy numbers $\tilde{A}=\left(a_{L}, a_{M}, a_{U}\right)$ and $\tilde{B}=\left(b_{L}, b_{M}, b_{U}\right)$ are said to be equal if and only if $a_{L}=b_{L}, a_{M}=b_{M}$ and $a_{U}=b_{U}[21]$.

Suppose $\tilde{A}=\left(a_{L}, a_{M}, a_{U}\right)$ and $\tilde{B}=\left(b_{L}, b_{M}, b_{U}\right)$ are two positive triangular fuzzy numbers, then basic fuzzy arithmetic operations on these fuzzy numbers are defined as follows $[5,10,21]$ :

$$
\begin{aligned}
& \text { Addition: } \tilde{A}+\tilde{B}=\left(a_{L}+b_{L}, a_{M}+b_{M}, a_{U}+b_{U}\right) \\
& \text { Subtraction: } \tilde{A}-\tilde{B}=\left(a_{L}-b_{L}, a_{M}-b_{M}, a_{U}-b_{U}\right) \\
& \text { Multiplication: } \tilde{A} \times \tilde{B}=\left(a_{L} b_{L}, a_{M} b_{M}, a_{U} b_{U}\right) ; \\
& \text { Division: } \tilde{A} / \tilde{B} \approx\left(\frac{a_{L}}{b_{U}}, \frac{a_{M}}{b_{M}}, \frac{a_{U}}{b_{L}}\right) \text {, such that } b_{L}, b_{M}, b_{U} \neq 0 .
\end{aligned}
$$

A ranking function is a function $U: F(R) \rightarrow R$, where $F(R)$ is a set of fuzzy numbers defined on set of real numbers, which maps each fuzzy number into the real line, where a natural order exists. Let $\tilde{A}=\left(a_{L}, a_{M}, a_{U}\right)$ be a triangular fuzzy number, then [24]:

$$
U(\tilde{A})=\frac{1}{4}\left(a_{L}+2 a_{M}+a_{U}\right) .
$$

The distance between two triangular fuzzy numbers $\tilde{A}=\left(a_{L}, a_{M}, a_{U}\right)$ and $\tilde{B}=\left(b_{L}, b_{M}, b_{U}\right)$ using vertex method is defined as [6]:

$$
d(\tilde{A}, \tilde{B})=\sqrt{\frac{1}{3}\left(\left(b_{L}-a_{L}\right)^{2}+\left(b_{M}-a_{M}\right)^{2}+\left(b_{U}-a_{U}\right)^{2}\right)} .
$$

There are different methods for normalizing triangular fuzzy number in FMCDM problems. In this paper we use the following method [6].

If $\tilde{x}_{i j}=\left(a_{i j}, b_{i j}, c_{i j}\right)(i=1, \ldots, m ; j=1, \ldots, n)$ are triangular fuzzy numbers, the normalization process is as follows:

$$
\begin{aligned}
& \left(\tilde{x}_{i j}\right)_{N}=\left(\left(a_{i j}\right)_{N},\left(b_{i j}\right)_{N},\left(c_{i j}\right)_{N}\right)=\left(\frac{a_{i j}}{c_{j}^{\operatorname{Max}}}, \frac{b_{i j}}{c_{j}^{\operatorname{Max}}}, \frac{c_{i j}}{c_{j}^{\operatorname{Max}}}\right), \quad i=1, \ldots, m ; j \in P, \\
& \left(\tilde{x}_{i j}\right)_{N}=\left(\left(a_{i j}\right)_{N},\left(b_{i j}\right)_{N},\left(c_{i j}\right)_{N}\right)=\left(\frac{a_{j}^{\mathrm{Min}}}{c_{i j}}, \frac{a_{j}^{\mathrm{Min}}}{b_{i j}}, \frac{a_{j}^{\mathrm{Min}}}{a_{i j}}\right), \quad i=1, \ldots, m ; j \in N,
\end{aligned}
$$


where $P$ and $N$ are sets of positive and negative criteria, respectively and

$$
a_{j}^{\mathrm{Min}}=\operatorname{Min}_{i} a_{i j}, c_{j}^{\mathrm{Max}}=\operatorname{Max}_{i} c_{i j}
$$

It should be noted that in above equations, $\left(\tilde{x}_{i j}\right)_{N}(i=1, \ldots, m ; j=1, \ldots, n)$ are the normalized fuzzy numbers related to the fuzzy numbers of $\tilde{x}_{i j}(i=1, \ldots, m ; j=1, \ldots, n)$.

\subsection{Fuzzy TOPSIS method: an overview}

The fuzzy TOPSIS method (FTOPSIS) was proposed by Chen [6] using the vertex method. The steps of his FTOPSIS are as below:

Step 1. Form a committee of decision makers, then identify the evaluation criteria.

Step 2. Choose the appropriate linguistic variables for the importance weight of the criteria and linguistic ratings for alternatives with respect to criteria.

Step 3. Determine the weight of each criterion based on the opinion of the decision makers.

Let $\tilde{W}=\left(\tilde{w}_{1}, \tilde{w}_{2}, \cdots, \tilde{w}_{n}\right)$ be weight vector, where $\tilde{w}_{j}, j=1, \ldots, n$ are linguistic variables. These linguistic variables can be described by triangular fuzzy numbers $\tilde{w}_{j}=\left(w_{j 1}, w_{j 2}, w_{j 3}\right)$.

Step 4. Construct the fuzzy decision matrix and normalized it.

$$
\begin{aligned}
& \begin{array}{llll}
C_{1} & C_{2} & \cdots & C_{n}
\end{array} \\
& \tilde{X}=\begin{array}{l}
A_{1} \\
A_{2} \\
\vdots \\
A_{m}
\end{array}\left(\begin{array}{lllll}
\tilde{x}_{11} & \tilde{x}_{12} & \cdots & \tilde{x}_{1 n} \\
\tilde{x}_{21} & \tilde{x}_{22} & \cdots & \tilde{x}_{2 n} \\
\vdots & \vdots & \vdots & \vdots \\
\tilde{x}_{m 1} & \tilde{x}_{m 2} & \cdots & \tilde{x}_{m n}
\end{array}\right)
\end{aligned}
$$

where $A_{i}$ is $i$-th alternative and $C_{j}$ is $j$-th criterion and $\tilde{x}_{i j}(i=1, \ldots, m ; j=1, \ldots, n)$ are linguistic variables which describe rating of alternative $A_{i}$ with respect to the criterion $C_{j}$. These linguistic variables can be expressed by triangular fuzzy numbers $\tilde{x}_{i j}=\left(a_{i j}, b_{i j}, c_{i j}\right)$. The normalized fuzzy decision matrix is shown by $\tilde{Y}=\left(\tilde{y}_{i j}\right)_{m \times n}$ and

$$
\begin{aligned}
& \tilde{y}_{i j}=\left(\left(a_{i j}\right)_{N},\left(b_{i j}\right)_{N},\left(c_{i j}\right)_{N}\right)=\left(\frac{a_{i j}}{c_{j}^{\operatorname{Max}}}, \frac{b_{i j}}{c_{j}^{\operatorname{Max}}}, \frac{c_{i j}}{c_{j}^{\operatorname{Max}}}\right), \quad i=1, \ldots, m ; j \in P, \\
& \tilde{y}_{i j}=\left(\left(a_{i j}\right)_{N},\left(b_{i j}\right)_{N},\left(c_{i j}\right)_{N}\right)=\left(\frac{a_{j}^{\mathrm{Min}}}{c_{i j}}, \frac{a_{j}^{\mathrm{Min}}}{b_{i j}}, \frac{a_{j}^{\mathrm{Min}}}{a_{i j}}\right), \quad i=1, \ldots, m ; j \in N,
\end{aligned}
$$

where $P$ and $N$ are sets of positive and negative criteria, respectively and

$$
a_{j}^{\mathrm{Min}}=\operatorname{Min}_{i} a_{i j}, c_{j}^{\mathrm{Max}}=\operatorname{Max}_{i} c_{i j}
$$

Step 5. Construct weighted normalized fuzzy decision matrix.

$$
\tilde{V}=\left(\tilde{v}_{i j}\right)_{m \times n}, \quad i=1, \ldots, m ; j=1, \ldots, n,
$$

where $\tilde{v}_{i j}=\tilde{y}_{i j} \cdot \tilde{w}_{j}$.

Step 6. Determine the FPIS and the FNIS.

FPIS and FNIS are shown respectively by $A^{*}=\left(\tilde{v}_{1}^{*}, \tilde{v}_{2}^{*}, \ldots, \tilde{v}_{n}^{*}\right)$ and $A^{-}=\left(\tilde{v}_{1}^{-}, \tilde{v}_{2}^{-}, \ldots, \tilde{v}_{n}^{-}\right)$, where $\tilde{v}_{j}^{*}=(1,1,1)$ and $\tilde{v}_{j}^{-}=(0,0,0), j=1, \ldots, n$. 
Step 7. Calculate the distance of each alternative from FPIS and FNIS by equation (2.9), respectively.

$$
d_{i}^{*}=\sum_{j=1}^{n} d\left(\tilde{v}_{i j}, \tilde{v}_{j}^{*}\right), \quad i=1, \ldots, m
$$

and

$$
d_{i}^{-}=\sum_{j=1}^{n} d\left(\tilde{v}_{i j}, \tilde{v}_{j}^{-}\right), \quad i=1, \ldots, m,
$$

where $d(\cdot, \cdot)$ is the distance measurement between two fuzzy numbers.

Step 8. Compute the closeness coefficient of each alternative.

$$
C C_{i}=\frac{d_{i}^{-}}{d_{i}^{*}+d_{i}^{-}}, \quad i=1, \ldots, m
$$

Step 9. According to the closeness coefficient, the ranking order of all alternatives can be determined.

\section{The PRoposed Method}

Suppose there are $m$ alternatives and $n$ criteria. Besides, we assume the fuzzy decision matrix $\tilde{X}$ is as below:

$$
\left.\begin{array}{ccccc} 
& C_{1} & C_{2} & \cdots & C_{n} \\
A_{1} & \tilde{x}_{11} & \tilde{x}_{12} & \cdots & \tilde{x}_{1 n} \\
A_{2} & \vdots \\
\tilde{x}_{21} & \tilde{x}_{22} & \cdots & \tilde{x}_{2 n} \\
\vdots & \vdots & \vdots & \vdots \\
A_{m} & \vdots & & \vdots \\
\tilde{x}_{m 1} & \tilde{x}_{m 2} & \cdots & \tilde{x}_{m n}
\end{array}\right)
$$

where $\tilde{x}_{i j}=\left(x_{i j}^{L}, x_{i j}^{M}, x_{i j}^{U}\right)$ is a positive fuzzy number and represent the performance of $i$-th alternative $A_{i}(i=1, \ldots, m)$ with respect to the $j$-th criterion $C_{j}(j=1, \ldots, n)$.

First, fuzzy decision matrix $\tilde{X}$ is transformed into a normal fuzzy matrix $\tilde{Y}=\left(\tilde{y}_{i j}\right)_{m \times n}$ by equations $(2.10)$ and (2.11),

$$
\begin{aligned}
& \begin{array}{llll}
C_{1} & C_{2} & \cdots & C_{n}
\end{array} \\
& \tilde{Y}=\begin{array}{l}
A_{1} \\
A_{2} \\
\vdots \\
A_{m}
\end{array}\left(\begin{array}{llll}
\tilde{y}_{11} & \tilde{y}_{12} & \cdots & \tilde{y}_{1 n} \\
\tilde{y}_{21} & \tilde{y}_{22} & \cdots & \tilde{y}_{2 n} \\
\vdots & \vdots & \vdots & \vdots \\
\tilde{y}_{m 1} & \tilde{y}_{m 2} & \cdots & \tilde{y}_{m n}
\end{array}\right) .
\end{aligned}
$$

Let $w_{j}$ be the weight of $j$-th criterion, based on SAW method [16] the score of $i$-th alternative is calculated by

$$
\tilde{S}_{i} \approx \sum_{j=1}^{n} w_{j} \tilde{y}_{i j}, \quad i=1, \ldots, m .
$$

Or,

$$
\tilde{S}_{i} \approx\left[S_{i}^{L}, S_{i}^{M}, S_{i}^{U}\right]=\left[\sum_{j=1}^{n} w_{j} y_{i j}^{L}, \sum_{j=1}^{n} w_{j} y_{i j}^{M}, \sum_{j=1}^{n} w_{j} y_{i j}^{U}\right], \quad i=1, \ldots, m .
$$

where $\tilde{S}_{i}$ is a triangular fuzzy number of $i$-th alternative. Without loss generality, we assume that $\tilde{S}_{i} \leq \tilde{1}$ for all alternatives $(i=1, \ldots, m)$ where $\tilde{1}$ is a triangular fuzzy number, e.g. $(0.95,1,1.05)$. Besides, we add 
constraints $w_{j}>0(j=1, \ldots, n)$ who determines a lower bound to avoid none of criteria weights becoming zero. Accordingly, in the optimistic case the score of each alternative can be obtained from the following model:

$$
\begin{array}{ll}
\text { Max: } & \tilde{S}_{p} \approx\left[S_{p}^{L}, S_{p}^{M}, S_{p}^{U}\right]=\left[\sum_{j=1}^{n} w_{j} y_{p j}^{L}, \sum_{j=1}^{n} w_{j} y_{p j}^{M}, \sum_{j=1}^{n} w_{j} y_{p j}^{U}\right] \\
\text { s.t. } & \tilde{S}_{i} \approx\left[S_{i}^{L}, S_{i}^{M}, S_{i}^{U}\right]=\left[\sum_{j=1}^{n} w_{j} y_{i j}^{L}, \sum_{j=1}^{n} w_{j} y_{i j}^{M}, \sum_{j=1}^{n} w_{j} y_{i j}^{U}\right] \leq(0.95,1,1.05), \quad i=1, \ldots, m, \\
& w_{j}>0, \quad j=1, \ldots, n .
\end{array}
$$

Similarly, corresponded to each alternative we obtain a pessimistic score as below:

$$
\begin{array}{ll}
\text { Min: } & \tilde{S}_{p} \approx\left[S_{p}^{L}, S_{p}^{M}, S_{p}^{U}\right]=\left[\sum_{j=1}^{n} w_{j} y_{p j}^{L}, \sum_{j=1}^{n} w_{j} y_{p j}^{M}, \sum_{j=1}^{n} w_{j} y_{p j}^{U}\right] \\
\text { s.t. } & \tilde{S}_{i} \approx\left[S_{i}^{L}, S_{i}^{M}, S_{i}^{U}\right]=\left[\sum_{j=1}^{n} w_{j} y_{i j}^{L}, \sum_{j=1}^{n} w_{j} y_{i j}^{M}, \sum_{j=1}^{n} w_{j} y_{i j}^{U}\right] \geq(0.95,1,1.05), \quad i=1, \ldots, m, \\
& w_{j}>0, \quad j=1, \ldots, n
\end{array}
$$

where the subscript $p$ represents the alternative under evaluation, i.e. $A_{p}$.

In the models (3.5) and (3.6), unlike conventional FMCDM models, the weight of the criteria for each alternative is derived objectively from the solution of the models.

To be noted that linear programming has been extended under different uncertainty frameworks in literature. For instance, one can see $[14,22,23,29,32]$.

The objective function models (3.5) and (3.6) by employing equation (2.8) are simplified as:

$$
\begin{aligned}
\operatorname{Max}: & S_{p}^{g}=\frac{1}{4} \sum_{j=1}^{n} w_{j}^{g}\left(y_{p j}^{L}+2 y_{p j}^{M}+y_{p j}^{U}\right) \\
\text { s.t. } & \tilde{S}_{i} \approx\left[S_{i}^{L}, S_{i}^{M}, S_{i}^{U}\right]=\left[\sum_{j=1}^{n} w_{j}^{g} y_{i j}^{L}, \sum_{j=1}^{n} w_{j}^{g} y_{i j}^{M}, \sum_{j=1}^{n} w_{j}^{g} y_{i j}^{U}\right] \leq(0.95,1,1.05), \quad i=1, \ldots, m, \\
& w_{j}^{g}>0, \quad j=1, \ldots, n,
\end{aligned}
$$

and,

$$
\begin{array}{ll}
\text { Min: } & S_{p}^{b}=\frac{1}{4} \sum_{j=1}^{n} w_{j}^{b}\left(y_{p j}^{L}+2 y_{p j}^{M}+y_{p j}^{U}\right) \\
\text { s.t. } & \tilde{S}_{i} \approx\left[S_{i}^{L}, S_{i}^{M}, S_{i}^{U}\right]=\left[\sum_{j=1}^{n} w_{j}^{b} y_{i j}^{L}, \sum_{j=1}^{n} w_{j}^{b} y_{i j}^{M}, \sum_{j=1}^{n} w_{j}^{b} y_{i j}^{U}\right] \geq(0.95,1,1.05), \quad i=1, \ldots, m, \\
& w_{j}^{b}>0, \quad j=1, \ldots, n
\end{array}
$$

were the $w^{g}$ and $w^{b}$ are weights vector in most favorable and least favorable for each alternative, respectively. 
Using triangular fuzzy slack variables $\tilde{t}_{i}=\left(t_{i}^{L}, t_{i}^{M}, t_{i}^{U}\right)$ and triangular fuzzy surplus variables $\tilde{r}_{i}=\left(r_{i}^{L}, r_{i}^{M}, r_{i}^{U}\right)$ the models (3.7) and (3.8), can be rewritten as below:

$$
\begin{array}{ll}
\operatorname{Max}: & S_{p}^{g}=\frac{1}{4} \sum_{j=1}^{n} w_{j}^{g}\left(y_{p j}^{L}+2 y_{p j}^{M}+y_{p j}^{U}\right), \\
\text { s.t. } & \tilde{S}_{i} \approx\left[S_{i}^{L}, S_{i}^{M}, S_{i}^{U}\right]=\left[\sum_{j=1}^{n} w_{j}^{g} y_{i j}^{L}, \sum_{j=1}^{n} w_{j}^{g} y_{i j}^{M}, \sum_{j=1}^{n} w_{j}^{g} y_{i j}^{U}\right]+\left[t_{i}^{L}, t_{i}^{M}, t_{i}^{U}\right]=(0.95,1,1.05), \\
& i=1, \ldots, m, w_{j}^{g}>0, \quad j=1, \ldots, n, \quad t_{i}^{L} \geq 0, t_{i}^{M}-t_{i}^{L} \geq 0, t_{i}^{U}-t_{i}^{M} \geq 0, \quad i=1, \ldots, m
\end{array}
$$

and,

$\operatorname{Min}: \quad S_{p}^{b}=\frac{1}{4} \sum_{j=1}^{n} w_{j}^{b}\left(y_{p j}^{L}+2 y_{p j}^{M}+y_{p j}^{U}\right)$,

$$
\begin{array}{ll}
\text { s.t. } & \tilde{S}_{i} \approx\left[S_{i}^{L}, S_{i}^{M}, S_{i}^{U}\right]=\left[\sum_{j=1}^{n} w_{j}^{b} y_{i j}^{L}, \sum_{j=1}^{n} w_{j}^{b} y_{i j}^{M}, \sum_{j=1}^{n} w_{j}^{b} y_{i j}^{U}\right]-\left[r_{i}^{L}, r_{i}^{M}, r_{i}^{U}\right]=(0.95,1,1.05), \\
& i=1, \ldots, m, w_{j}^{b}>0, \quad j=1, \ldots, n, \quad r_{i}^{L} \geq 0, r_{i}^{M}-r_{i}^{L} \geq 0, r_{i}^{U}-r_{i}^{M} \geq 0, \quad i=1, \ldots, m .
\end{array}
$$

Using equation (2.3) and arithmetic operations defined in equations (2.4)-(2.7), the models (3.9) and (3.10) are converted into the following LP models:

$$
\begin{aligned}
\operatorname{Max}: \quad S_{p}^{g}= & \frac{1}{4} \sum_{j=1}^{n} w_{j}^{g}\left(y_{p j}^{L}+2 y_{p j}^{M}+y_{p j}^{U}\right) \\
\text { s.t. } \quad S_{i}^{L}= & \sum_{j=1}^{n} w_{j}^{g} y_{i j}^{L}+t_{i}^{L}=0.95, \quad i=1, \ldots, m \\
S_{i}^{M}= & \sum_{j=1}^{n} w_{j}^{g} y_{i j}^{M}+t_{i}^{M}=1, \quad i=1, \ldots, m, \\
S_{i}^{U}= & \sum_{j=1}^{n} w_{j}^{g} y_{i j}^{U}+t_{i}^{U}=1.05, \quad i=1, \ldots, m, \quad w_{j}^{g}>0, \quad j=1, \ldots, n, \\
& t_{i}^{L} \geq 0, t_{i}^{M}-t_{i}^{L} \geq 0, t_{i}^{U}-t_{i}^{M} \geq 0, \quad i=1, \ldots, m .
\end{aligned}
$$

and,

$\operatorname{Min}: S_{p}^{b}=\frac{1}{4} \sum_{j=1}^{n} w_{j}^{b}\left(y_{p j}^{L}+2 y_{p j}^{M}+y_{p j}^{U}\right)$,

$$
\begin{aligned}
\text { s.t. } & S_{i}^{L}= \\
S_{i}^{M}= & \sum_{j=1}^{n} w_{j}^{b} y_{i j}^{L}+r_{j}^{b} y_{i j}^{M}+r_{i}^{M}=1, \quad i=1, \ldots, m, \\
S_{i}^{U}= & \sum_{j=1}^{n} w_{j}^{b} y_{i j}^{U}+r_{i}^{U}=1.05, \quad i=1, \ldots, m, \\
& w_{j}^{b}>0, \quad j=1, \ldots, n, \quad r_{i}^{L} \geq 0, r_{i}^{M}-r_{i}^{L} \geq 0, r_{i}^{U}-r_{i}^{M} \geq 0, \quad i=1, \ldots, m .
\end{aligned}
$$


The optimal weights $w_{j}^{g^{*}}$ are obtained by solving model (3.11) and the optimal objective value, $S_{P}^{g^{*}}$, shows the optimistic score of alternative $A_{p}$. By solving model (3.11) for each alternative, the optimistic score associated with each alternative is derived. Similarly, solving model (3.12) leads to pessimistic score $S_{P}^{b^{*}}$ for alternative $A_{p}$. Indeed in model (3.12), each alternative has a set of weights $w_{j}^{b^{*}}$ which are least favorable.

Since $S_{P}^{g^{*}}$ and $S_{P}^{b^{*}}$ are respectively based on the weights that are most favorable and least favorable for the $p$-th alternative, we may, respectively, term them as the "good score" and "bad score" for FMCDM problem. Furthermore, we can build a composite score by combining the two extreme cases in the following way:

$$
S_{p}^{\mathrm{AM}}=\frac{1}{2}\left(S_{p}^{g^{*}}+S_{p}^{b^{*}}\right), \quad p=1, \ldots, m .
$$

In fact, we employ the arithmetic mean, due to its simplicity, to compute the final score of each alternative. Clearly, the DM may calculate the final score using other methods such geometric mean.

In sum, an algorithm of the multi-person multi-criteria decision making with fuzzy set approach is given in the following:

Step 1. Form a committee of $K$ decision makers, then identify the evaluation criteria.

Step 2. Choose the appropriate linguistic ratings for alternatives with respect criteria (shown as Tab. 2).

Step 3. Pool the decision makers' opinions to get the aggregated fuzzy rating $\tilde{x}_{i j}$ of alternative $A_{i}$ under criterion $C_{j}$ and $\tilde{x}_{i j}=\left[\tilde{x}_{i j}^{1}+\tilde{x}_{i j}^{2}+\cdots+\tilde{x}_{i j}^{K}\right] / K$ where $\tilde{x}_{i j}^{k}$ is the rating of the $k$-th DM, $k=1,2, \ldots, K$.

Step 4. Construct the fuzzy decision matrix (3.1) and the normalized fuzzy decision matrix (3.2) by equations (2.10) and (2.11).

Step 5. Determine the optimal weight vectors $w^{g^{*}}$ and $w^{b^{*}}$ for criteria in optimistic and pessimistic viewpoints by solving models (3.11) and (3.12).

Step 6. Calculated the good score, $S^{g^{*}}$, and the bad score, $S^{b^{*}}$, for each alternative in optimistic and pessimistic viewpoints by solving models (3.11) and (3.12).

Step 7. Calculated the composite score, $S^{\mathrm{AM}}$, for each alternative by equation (3.13).

Step 8. According to the composite score, the ranking order of all alternatives can be determined.

\section{COMPARISON WITH FUZZY TOPSIS}

- The fuzzy TOPSIS method seeks a compromise solution based on closeness to positive ideal solution and remoteness from negative ideal solution, simultaneously. But the proposed method does not look for the positive and negative ideal solutions to get the distance from each alternative. In proposed method the LP models provide automatically good score and bad score of each alternative.

- In the proposed method, unlike the fuzzy TOPSIS method, which determines the weight of each criterion by the experts, the weight of the criteria is derived objectively from the solution of the LP models.

- The fuzzy TOPSIS method employs a fixed weight vector while in the proposed method, the weight vector differs from an alternative to another.

- Both methods use the same fuzzy linear normalization by equations (2.10) and (2.11).

- To rank alternatives the fuzzy TOPSIS method use the closeness coefficient index, but the proposed method utilizes the arithmetic mean of good score and bad score for each alternative.

\section{Illustrative EXAMPLES}

In this section the proposed method is illustrated using three numerical examples. The first two examples are taken from literature and the last one is associated to a real case.

Example 1. Reconsider the example investigated by Chen [6], in which a software company desires to hire a system analysis engineer among from three candidates $A_{1}, A_{2}$ and $A_{3}$. A committee of three decision makers 
TABLE 1. Linguistic variables for the relative importance weights of criteria.

\begin{tabular}{ll}
\hline \hline Linguistic variable & Fuzzy number \\
\hline Very low (VL) & $(0.00,0.00,0.10)$ \\
Low (L) & $(0.00,0.10,0.30)$ \\
Medium low (ML) & $(0.10,0.30,0.50)$ \\
Medium (M) & $(0.30,0.50,0.70)$ \\
Medium high (MH) & $(0.50,0.70,0.90)$ \\
High (H) & $(0.70,0.90,1.00)$ \\
Very high (VH) & $(0.90,1.00,1.00)$ \\
\hline
\end{tabular}

TABLE 2. Linguistic variables for the ratings.

\begin{tabular}{ll}
\hline \hline Linguistic variable & Fuzzy number \\
\hline Very poor (VP) & $(0.00,0.00,1.00)$ \\
Poor (P) & $(0.00,1.00,3.00)$ \\
Medium poor (MP) & $(1.00,3.00,5.00)$ \\
Fair (F) & $(3.00,5.00,7.00)$ \\
Medium good (MG) & $(5.00,7.00,9.00)$ \\
Good (G) & $(7.00,9.00,10.00)$ \\
Very good (VG) & $(9.00,10.00,10.00)$ \\
\hline
\end{tabular}

TABLE 3. Ratings of three alternatives with respect to the criteria and normalized fuzzy ratings for Example 1.

\begin{tabular}{|c|c|c|c|c|c|c|c|}
\hline \multirow[t]{2}{*}{ Criteria } & \multirow[t]{2}{*}{ Alternatives } & \multicolumn{3}{|c|}{$\mathrm{DMs}$} & \multirow{2}{*}{$\begin{array}{l}\text { Aggregated } \\
\text { fuzzy } \\
\text { numbers }\end{array}$} & \multirow{2}{*}{$\begin{array}{l}\text { Normalized } \\
\text { fuzzy } \\
\text { numbers }\end{array}$} & \multirow{2}{*}{$\begin{array}{l}\text { Weight } \\
\text { W }\end{array}$} \\
\hline & & DM 1 & DM 2 & DM 3 & & & \\
\hline \multirow{3}{*}{$C_{1}$} & $A_{1}$ & MG & G & MG & $(5.70,7.70,9.30)$ & $(0.59,0.79,0.96)$ & \multirow{3}{*}{$(0.70,0.90,1.00)$} \\
\hline & $A_{2}$ & G & G & MG & $(6.30,8.30,9.70)$ & $(0.65,0.86,1.00)$ & \\
\hline & $A_{3}$ & VG & G & $\mathrm{F}$ & $(6.30,8.00,9.00)$ & $(0.65,0.82,0.93)$ & \\
\hline \multirow{3}{*}{$C_{2}$} & $A_{1}$ & G & MG & $\mathrm{F}$ & $(5.00,7.00,9.00)$ & $(0.50,0.70,0.90)$ & \multirow{3}{*}{$(0.90,1.00,1.00)$} \\
\hline & $A_{2}$ & VG & VG & VG & $(9.00,10.00,10.00)$ & $(0.90,1.00,1.00)$ & \\
\hline & $A_{3}$ & MG & $\mathrm{G}$ & $\mathrm{VG}$ & $(7.00,9.00,10.00)$ & $(0.70,0.90,1.00)$ & \\
\hline \multirow{3}{*}{$C_{3}$} & $A_{1}$ & $\mathrm{~F}$ & G & G & $(5.70,7.70,9.00)$ & $(0.57,0.77,0.90)$ & \multirow{3}{*}{$(0.77,0.93,1.00)$} \\
\hline & $A_{2}$ & VG & VG & G & $(8.30,9.70,10.00)$ & $(0.83,0.97,1.00)$ & \\
\hline & $A_{3}$ & G & MG & VG & $(7.00,9.00,10.00)$ & $(0.70,0.90,1.00)$ & \\
\hline \multirow{3}{*}{$C_{4}$} & $A_{1}$ & VG & $\mathrm{G}$ & VG & $(8.33,9.67,10.00)$ & $(0.83,0.97,1.00)$ & \multirow{3}{*}{$(0.90,1.00,1.00)$} \\
\hline & $A_{2}$ & VG & VG & $\mathrm{VG}$ & $(9.00,10.00,10.00)$ & $(0.90,1.00,1.00)$ & \\
\hline & $A_{3}$ & G & VG & MG & $(7.00,9.00,10.00)$ & $(0.70,0.90,1.00)$ & \\
\hline \multirow{3}{*}{$C_{5}$} & $A_{1}$ & $\mathrm{~F}$ & $\mathrm{~F}$ & $\mathrm{~F}$ & $(3.00,5.00,7.00)$ & $(0.30,0.50,0.70)$ & \multirow{3}{*}{$(0.43,0.63,0.83)$} \\
\hline & $A_{2}$ & VG & MG & G & $(7.00,9.00,10.00)$ & $(0.70,0.90,1.00)$ & \\
\hline & $A_{3}$ & G & G & MG & $(6.30,8.30,9.70)$ & $(0.63,0.83,0.97)$ & \\
\hline
\end{tabular}

has been set up to interview and select the most suitable candidate. They are evaluated by the following five positive criteria:

Emotional steadiness $\left(C_{1}\right)$, Oral communication skill $\left(C_{2}\right)$, Personality $\left(C_{3}\right)$, Past experience $\left(C_{4}\right)$ and Selfconfidence $\left(C_{5}\right)$. 
TABLE 4. The final score and rank of each alternative for Example 1.

\begin{tabular}{|c|c|c|c|c|}
\hline \multirow{3}{*}{ Alternatives } & \multicolumn{3}{|c|}{ Proposed method } & \multirow{3}{*}{$\begin{array}{l}\text { Chen's method } \\
\text { Final score }\end{array}$} \\
\hline & Good score & Bad score & Final score & \\
\hline & $S_{p}^{g^{*}}$ & $S_{p}^{b^{*}}$ & $S_{p}^{\mathrm{AM}}$ & \\
\hline$A_{1}$ & $0.2341(2)$ & $1.1439(1)$ & $0.6890(3)$ & $0.62(3)$ \\
\hline$A_{2}$ & $0.2431(1)$ & $1.2609(3)$ & $0.7520(1)$ & $0.77(1)$ \\
\hline$A_{3}$ & $0.2256(3)$ & $1.1827(2)$ & $0.7041(2)$ & $0.71(2)$ \\
\hline
\end{tabular}

TABle 5. The fuzzy decision matrix for Example 2.

\begin{tabular}{lllllll}
\hline \hline Alternatives & $C_{1}$ & $C_{2}$ & $C_{3}$ & $C_{4}$ & $C_{5}$ & $C_{6}$ \\
\hline $\mathrm{W}$ & $(0.60,0.675,0.75)$ & $(0.40,0.50,0.60)$ & $(0.40,0.50,0.60)$ & $(0.40,0.50,0.60)$ & $(0.75,0.825,0.90)$ & $(0.90,0.95,1.00)$ \\
$A_{1}$ & 2.00 & 1500 & 20000 & 5.50 & $(0.30,0.50,0.70)$ & $(0.90,0.95,1.00)$ \\
$A_{2}$ & 2.50 & 2700 & 18000 & 6.50 & $(0.10,0.20,0.30)$ & $(0.30,0.50,0.70)$ \\
$A_{3}$ & 1.80 & 2000 & 21000 & 4.50 & $(0.70,0.80,0.90)$ & $(0.70,0.80,0.90)$ \\
$A_{4}$ & 2.20 & 1800 & 20000 & 5.00 & $(0.30,0.50,0.70)$ & $(0.30,0.50,0.70)$ \\
\hline
\end{tabular}

TABLE 6 . The normalized fuzzy decision matrix for Example 2.

\begin{tabular}{lllllll}
\hline \hline Alternatives & $C_{1}$ & $C_{2}$ & $C_{3}$ & $C_{4}$ & $C_{5}$ & $C_{6}$ \\
\hline$A_{1}$ & $(0.80,0.80,0.80)$ & $(0.56,0.56,0.56)$ & $(0.95,0.95,0.95)$ & $(0.82,0.82,0.82)$ & $(0.33,0.56,0.78)$ & $(0.90,0.95,1.00)$ \\
$A_{2}$ & $(1.00,1.00,1.00)$ & $(1.00,1.00,1.00)$ & $(0.86,0.86,0.86)$ & $(0.69,0.69,0.69)$ & $(0.11,0.22,0.33)$ & $(0.30,0.50,0.70)$ \\
$A_{3}$ & $(0.72,0.72,0.72)$ & $(0.74,0.74,0.74)$ & $(1.00,1.00,1.00)$ & $(1.00,1.00,1.00)$ & $(0.78,0.89,1.00)$ & $(0.70,0.80,0.90)$ \\
$A_{4}$ & $(0.88,0.88,0.88)$ & $(0.67,0.67,0.67)$ & $(0.95,0.95,0.95)$ & $(0.90,0.90,0.90)$ & $(0.33,0.56,0.78)$ & $(0.30,0.50,0.70)$ \\
\hline
\end{tabular}

TABLE 7. The final score and rank of each alternative for Example 2.

\begin{tabular}{|c|c|c|c|c|}
\hline \multirow{3}{*}{ Alternatives } & \multicolumn{3}{|c|}{ Proposed method } & \multirow{3}{*}{$\begin{array}{l}\text { Chen's method } \\
\text { Final score }\end{array}$} \\
\hline & Good score & Bad score & Final score & \\
\hline & $S_{p}^{g^{*}}$ & $S_{p}^{b^{*}}$ & $S_{p}^{\mathrm{AM}}$ & \\
\hline$A_{1}$ & $0.9829(3)$ & $1.0195(2)$ & $1.0012(3)$ & $0.51(2)$ \\
\hline$A_{2}$ & $0.9997(1)$ & $1.0003(1)$ & $1.0000(4)$ & $0.44(4)$ \\
\hline$A_{3}$ & $0.9748(4)$ & $1.0574(4)$ & $1.0161(2)$ & $0.56(1)$ \\
\hline$A_{4}$ & $0.9993(2)$ & $1.0514(3)$ & $1.0254(1)$ & $0.47(3)$ \\
\hline
\end{tabular}

The relative importance weights of the five criteria are described based on linguistic variables as defined in Table 1. The values of each criterion are also shown by the linguistic variables as defined in Table 2 . Three decision makers (DMs) independently declare their opinion on the weight of each criterion and the value of each candidate for each criterion using the linguistic variables given in Tables 1 and 2. (In the proposed method, the weights are obtained directly from the optimal solutions of the models).

The integrated fuzzy opinions of the three DMs, and normalized fuzzy numbers, are shown in Table 3 . In Table 4, the final scores obtained from combining the optimal solution of models (3.11) and (3.12) and the ranking of alternatives and comparison with the Chen's method are shown. The numbers in parentheses in Table 4 are the corresponding ranks. As we see in Table 4, all alternatives have a same rank in both methods. The ranking of alternatives in the proposed method and in the Chen's method is $A_{2} \succ A_{3} \succ A_{1}$. 
TABLE 8. Ratings of five alternatives with respect to the criteria and normalized fuzzy ratings for Example 3.

\begin{tabular}{|c|c|c|c|c|c|c|}
\hline \multirow[t]{2}{*}{ Criteria } & \multirow[t]{2}{*}{ Alternatives } & \multicolumn{3}{|c|}{$\mathrm{DMs}$} & \multirow{2}{*}{ Aggregated fuzzy numbers } & \multirow[t]{2}{*}{ Normalized fuzzy numbers } \\
\hline & & DM 1 & DM 2 & DM 3 & & \\
\hline \multirow{5}{*}{$C_{1}$} & $A_{1}$ & VG & $\mathrm{VG}$ & G & $(8.33,9.67,10.00)$ & $(0.833,0.967,1.000)$ \\
\hline & $A_{2}$ & VG & G & G & $(7.67,9.33,10.00)$ & $(0.767,0.933,1.000)$ \\
\hline & $A_{3}$ & MP & $\mathrm{P}$ & MP & $(0.67,2.33,4.33)$ & $(0.067,0.233,0.433)$ \\
\hline & $A_{4}$ & $\mathrm{~F}$ & MP & $\mathrm{F}$ & $(2.33,4.33,6.33)$ & $(0.233,0.433,0.633)$ \\
\hline & $A_{5}$ & $\mathrm{P}$ & MP & MP & $(0.67,2.33,4.33)$ & $(0.067,0.233,0.433)$ \\
\hline \multirow{5}{*}{$C_{2}$} & $A_{1}$ & $\mathrm{~F}$ & MG & G & $(5.00,7.00,8.67)$ & $(0.500,0.700,0.867)$ \\
\hline & $A_{2}$ & $\mathrm{G}$ & G & MG & $(6.33,8.33,9.67)$ & $(0.633,0.833,0.967)$ \\
\hline & $A_{3}$ & G & MG & G & $(6.33,8.33,9.67)$ & $(0.633,0.833,0.967)$ \\
\hline & $A_{4}$ & MP & $\mathrm{F}$ & $\mathrm{F}$ & $(2.33,4.33,6.33)$ & $(0.233,0.433,0.633)$ \\
\hline & $A_{5}$ & VG & VG & VG & $(9.00,10.00,10.00)$ & $(0.900,1.000,1.000)$ \\
\hline \multirow{5}{*}{$C_{3}$} & $A_{1}$ & $\mathrm{G}$ & MG & MG & $(5.67,7.67,9.33)$ & $(0.567,0.767,0.933)$ \\
\hline & $A_{2}$ & $\mathrm{~F}$ & $\mathrm{~F}$ & MG & $(3.67,5.67,7.67)$ & $(0.367,0.567,0.767)$ \\
\hline & $A_{3}$ & $\mathrm{~F}$ & $\mathrm{~F}$ & MP & $(2.33,4.33,6.33)$ & $(0.233,0.433,0.633)$ \\
\hline & $A_{4}$ & VG & $\mathrm{VG}$ & G & $(8.33,9.67,10.00)$ & $(0.833,0.967,1.000)$ \\
\hline & $A_{5}$ & $\mathrm{~F}$ & MG & MG & $(4.33,6.33,8.33)$ & $(0.433,0.633,0.833)$ \\
\hline \multirow{5}{*}{$C_{4}$} & $A_{1}$ & G & G & $\mathrm{VG}$ & $(7.67,9.33,10.00)$ & $(0.767,0.933,1.000)$ \\
\hline & $A_{2}$ & $\mathrm{~F}$ & MP & $\mathrm{F}$ & $(2.33,4.33,6.33)$ & $(0.233,0.433,0.633)$ \\
\hline & $A_{3}$ & MP & $\mathrm{P}$ & $\mathrm{P}$ & $(0.33,1.67,3.67)$ & $(0.033,0.167,0.367)$ \\
\hline & $A_{4}$ & $\mathrm{G}$ & $\mathrm{G}$ & $\mathrm{G}$ & $(7.00,9.00,10.00)$ & $(0.700,0.900,1.000)$ \\
\hline & $A_{5}$ & VG & G & VG & $(8.33,9.67,10.00)$ & $(0.833,0.967,1.000)$ \\
\hline \multirow{5}{*}{$C_{5}$} & $A_{1}$ & $\mathrm{P}$ & MP & $\mathrm{F}$ & $(1.33,3.00,5.00)$ & $(0.133,0.300,0.500)$ \\
\hline & $A_{2}$ & $\mathrm{VG}$ & $\mathrm{G}$ & G & $(7.67,9.33,10.00)$ & $(0.767,0.933,1.000)$ \\
\hline & $A_{3}$ & $\mathrm{VG}$ & $\mathrm{VG}$ & $\mathrm{G}$ & $(8.33,9.67,10.00)$ & $(0.833,0.967,1.000)$ \\
\hline & $A_{4}$ & $\mathrm{~F}$ & $\mathrm{~F}$ & MP & $(2.33,4.33,6.33)$ & $(0.233,0.433,0.633)$ \\
\hline & $A_{5}$ & MG & $\mathrm{F}$ & $\mathrm{F}$ & $(3.67,5.67,7.67)$ & $(0.367,0.567,0.767)$ \\
\hline \multirow{5}{*}{$C_{6}$} & $A_{1}$ & VG & VG & VG & $(9.00,10.00,10.00)$ & $(0.900,1.000,1.000)$ \\
\hline & $A_{2}$ & MG & MG & MG & $(5.00,7.00,9.00)$ & $(0.500,0.700,0.900)$ \\
\hline & $A_{3}$ & MG & MG & $\mathrm{F}$ & $(4.33,6.33,8.33)$ & $(0.433,0.633,0.833)$ \\
\hline & $A_{4}$ & G & G & MG & $(6.33,8.33,9.67)$ & $(0.633,0.833,0.967)$ \\
\hline & $A_{5}$ & MP & $\mathrm{P}$ & MP & $(0.67,2.33,4.33)$ & $(0.067,0.233,0.433)$ \\
\hline \multirow{5}{*}{$C_{7}$} & $\overline{A_{1}}$ & $\mathrm{VG}$ & $\mathrm{VG}$ & $\mathrm{G}$ & $(8.33,9.67,10.00)$ & $(0.833,0.967,1.000)$ \\
\hline & $A_{2}$ & $\mathrm{G}$ & MG & MG & $(5.67,7.67,9.33)$ & $(0.567,0.767,0.933)$ \\
\hline & $A_{3}$ & MP & $\mathrm{F}$ & MP & $(1.67,3.67,5.67)$ & $(0.167,0.367,0.567)$ \\
\hline & $A_{4}$ & $\mathrm{G}$ & MG & G & $(6.33,8.33,9.67)$ & $(0.633,0.833,0.967)$ \\
\hline & $A_{5}$ & $\mathrm{G}$ & MG & MG & $(5.67,7.67,9.33)$ & $(0.567,0.767,0.933)$ \\
\hline \multirow{5}{*}{$C_{8}$} & $A_{1}$ & $\mathrm{~F}$ & MG & $\mathrm{F}$ & $(3.67,5.67,7.67)$ & $(0.367,0.567,0.767)$ \\
\hline & $A_{2}$ & MG & G & MG & $(5.67,7.67,9.33)$ & $(0.567,0.767,0.933)$ \\
\hline & $A_{3}$ & $\mathrm{VG}$ & $\mathrm{G}$ & G & $(7.67,9.33,10.00)$ & $(0.767,0.933,1.000)$ \\
\hline & $A_{4}$ & $\mathrm{~F}$ & $\mathrm{~F}$ & $\mathrm{~F}$ & $(3.00,5.00,7.00)$ & $(0.300,0.500,0.700)$ \\
\hline & $A_{5}$ & $\mathrm{~F}$ & MG & $\mathrm{F}$ & $(3.67,5.67,7.67)$ & $(0.367,0.567,0.767)$ \\
\hline
\end{tabular}

Example 2. Reconsider the example by Chen and Hwang [7], where a country wants to buy fighter jets by taking into account the following six criteria:

Maximum speed $\left(C_{1}\right)$, Ferry range $\left(C_{2}\right)$, Maximum payload $\left(C_{3}\right)$, Price $\left(C_{4}\right)$, Reliability $\left(C_{5}\right)$ and Maneuverability $\left(C_{6}\right)$.

The fourth criterion is negative and the other criteria are positive. Four jet aircraft types are evaluated under the above criteria. The fuzzy decision matrix is depicted in Table 5 and the normalized fuzzy matrix is shown in 
TABLE 9. The final score and rank of each alternative for Example 3.

\begin{tabular}{|c|c|c|c|}
\hline \multirow{3}{*}{ Alternatives } & \multicolumn{3}{|c|}{ Proposed method } \\
\hline & Good Score & Bad Score & Final Score \\
\hline & $S_{p}^{g^{*}}$ & $S_{p}^{b^{*}}$ & $S_{p}^{\mathrm{AM}}$ \\
\hline$A_{1}$ & $0.2421(1)$ & $1.2484(3)$ & $0.7453(2)$ \\
\hline$A_{2}$ & $0.2255(5)$ & $1.3097(5)$ & $0.7676(1)$ \\
\hline$A_{3}$ & $0.2323(4)$ & $1.2249(2)$ & $0.7286(4)$ \\
\hline$A_{4}$ & $0.2330(3)$ & $1.2572(4)$ & $0.7451(3)$ \\
\hline$A_{5}$ & $0.2407(2)$ & $1.2054(1)$ & $0.7231(5)$ \\
\hline
\end{tabular}

Table 6. We show our findings and those obtained by Chen in Table 7. Based on Table 7, the alternative $A_{2}$ has the same rank in both methods. Our ranking is $A_{4} \succ A_{3} \succ A_{1} \succ A_{2}$ and Chen's ranking is $A_{3} \succ A_{1} \succ A_{4} \succ A_{2}$. The difference in ranking of the two approaches is because of the weight generation and the schemes of score computing.

Example 3. In the recent years, people's demands for dairy products, such as milk, yogurt, cheese, butter and ice cream, is increasing substantially. Determining a suitable location to establish a dairy factory to respond to the demand growth is of particular importance for a secure and appropriate investment.

In this section, a real case study has been conducted in Iran. The issue is the determination of an industrial zone among five industrial zones in different cities of Iran, which are candidates for the establishment of dairy products. All five industrial zones are evaluated by a panel of three industry engineers (DMs) with eight positive criteria. Criteria are:

Close proximity to raw materials $\left(C_{1}\right)$, Close proximity to dairy product markets $\left(C_{2}\right)$, Government policies on each industrial zone $\left(C_{3}\right)$, Competition conditions $\left(C_{4}\right)$, Transportation facilities $\left(C_{5}\right)$, Climatic conditions $\left(C_{6}\right)$, The possibility of developing factory $\left(C_{7}\right)$ and Availability of expert workforce $\left(C_{8}\right)$.

Rates of the criteria are characterized by the linguistic variables defined in Table 2 . The original assessments information, presented by three industrial engineers, is shown in Table 8. The integration of fuzzy numbers is obtained by the average fuzzy opinions of three DMs. That is, $\tilde{x}_{i j}=\left(\tilde{x}_{i j}^{1}+\tilde{x}_{i j}^{2}+\tilde{x}_{i j}^{3}\right) / 3$, where $\tilde{x}_{i j}^{k}$ is the rating given by the $k$-th DM. In Table 9, the final scores obtained from combining the optimal solution of models (3.11) and (3.12) and the ranking of the alternative are shown. The ranking of alternatives using models (3.11) and (3.12) and equation (3.13) is $A_{2} \succ A_{1} \succ A_{4} \succ A_{3} \succ A_{5}$. Hence, the second industrial zone $\left(A_{2}\right)$ has a highest chance of being selected as a location for constructing dairy product factory.

\section{Conclusions}

MCDM is widely used to solve real-world decision-making problems. It should be noted that in reality, accurate data for real problems is not always available and we usually deal with inaccurate data and incomplete information. In such situations, the fuzzy MCDM methods are used to solve the fuzzy MCDM problems. In this paper, we transformed a FMCDM problem into two linear programming models. The two models easily calculate good score and bad score for each alternative. Using the arithmetic mean of good score and bad score, we rank the alternatives. Three numerical examples were given to show applicability of the proposed method. The purpose of presenting two first numerical examples was to comparing the proposed method with the fuzzy TOPSIS. We found that the fuzzy TOPSIS method seeks a compromise solution based on closeness to PIS and remoteness from NIS, simultaneously. But, the proposed method does not look for the PIS and NIS to get the distance from each alternative. Indeed, the proposed method by solving two LPs provides automatically the good score and bad score of each alternative in optimistic and pessimistic cases. Finally, this is worthy to pointing out that the proposed method can even be used to solve an FMCDM problem whose weight criteria are 
not already specified. The disadvantage of the proposed model is that by increasing the number of alternatives the DM concern with the high number of LP models (the number of LPs is twice of alternatives). For future research one can extend the proposed model for other fuzzy environments, such as type-2 fuzzy numbers.

Acknowledgements. The authors would like to thank two anonymous referees for their helpful comments and suggestions which improved the first version of this study.

\section{REFERENCES}

[1] M. Akbari, S. Molla-Alizadeh-Zavardehi and S. Niroomand, Meta-heuristic approaches for fixed-charge solid transportation problem in two-stage supply chain network. Oper. Res. 20 (2020) 447-471.

[2] F.J. Arroyo-Canada and J. Gil-Lafuente, A fuzzy asymmetric TOPSIS model for optimizing investment in online advertising campaigns. OR (2017) 1-16.

[3] M. Arslan and M. Çunkaş, Performance evaluation of sugar plants by fuzzy technique for order performance by similarity to ideal solution (TOPSIS). Cyber. Syst. 43 (2012) 529-548.

[4] I. Beg and T. Rashid, Modelling uncertainties in multi-criteria decision making using distance measure and TOPSIS for hesitant fuzzy sets. Arti. Intel Soft Comp. Res. 7 (2017) 103-109.

[5] D.Y. Chang, Applications of the extent analysis method on fuzzy AHP. Eur. J. Oper. Res. 95 (1996) 649-655.

[6] C.T. Chen, Extensions of the TOPSIS for group decision-making under fuzzy environment. Fuzzy Sets Syst. 114 (2000) 1-9.

[7] S.J. Chen and C.L. Hwang, Fuzzy Multiple Attribute Decision Making. Vol. 375 of Lecture Notes in Economics and Mathematical Systems. Springer, Berlin-Heidelberg (1992).

[8] T.Y. Chou, C.L. Hsu and M.C. Chen, A fuzzy multi-criteria decision model for international tourist hotels location selection. Int. J. Hosp. Manag. 27 (2008) 293-301.

[9] D. Dalalah, M. Hayajneh and F. Batieha, A fuzzy multi-criteria decision making model for supplier selection. Expert Syst. Appl. 38 (2011) 8384-8391.

[10] D. Dubois and H. Prade, Fuzzy Sets and Systems: Theory and Application. Academic Press, New York, NY (1980).

[11] G. Dwivedi, R.K. Srivastava and S.K. Srivastava, A generalised fuzzy TOPSIS with improved closeness coefficient. Expert Syst. Appl. 96 (2018) 185-195.

[12] L. Fang and H. Li, Multi-criteria decision analysis for efficient location-allocation problem combining DEA and goal programming. RAIRO:OR 49 (2015) 753-772.

[13] A. Hadi-Vencheh and M.N. Mokhtarian, A new fuzzy MCDM approach based on centroid of fuzzy numbers. Expert Syst. Appl. 38 (2011) 5226-5230.

[14] S.H.R. Hajiagha, H.A. Mahdiraji, S.S. Hashemi and E.K. Zavadskas, Evolving a linear programming technique for MAGDM problems with interval valued intuitionistic fuzzy information. Expert Syst. Appl. 42 (2015) 9318-9325.

[15] H. Han and S. Trimi, A fuzzy TOPSIS method for performance evaluation of reverse logistics in social commerce platforms. Expert Syst. Appl. 103 (2018) 133-145.

[16] A. Hatami-Marbini and F. Kangi, An extension of fuzzy TOPSIS for a group decision making with an application to Tehran stock exchange. Appl. Soft Comp. 52 (2017) 1084-1097.

[17] C.L. Hwang and K. Yoon, Multiple Attribute Decision Making Methods and Applications A State-of-the-Art Survey. Vol. 186 of Lecture Notes in Economics and Mathematical Systems. Springer, Berlin-Heidelberg (1981).

[18] G.R. Jahanshahloo, F. Hosseinzadeh Lotfi and M. Izadikhah, Extension of the TOPSIS method for decision-making problems with fuzzy data. Appl Math. Comp. 181 (2006) 1544-1551.

[19] D. Joshi and S. Kumar, Improved accuracy function for interval-valued intuitionistic fuzzy sets and its application to multiattributes group decision making. Cyber. Syst. 49 (2018) 64-76.

[20] M. Kabak, E. Köse, O. Kırılmaz and S. Burmaoğlu, A fuzzy multi-criteria decision making approach to assess building energy performance. Ener. Build. 72 (2014) 382-389.

[21] A. Kauffman and M.M. Gupta, Introduction to Fuzzy Arithmetic: Theory and Application. Van Nostrand Reinhold, New York, NY (1991).

[22] H.A. Khalifa, Utilizing a new approach for solving fully fuzzy linear programming problems. C OR Rev. 10 (2019) 337-344.

[23] A. Kumar, J. Kaur and P. Singh, A new method for solving fully fuzzy linear programming problems. Appl. Math. Model. 35 (2011) 817-823.

[24] T.S. Liou and M.J.J. Wang, Ranking fuzzy numbers with integral value. Fuzzy Sets Syst. 50 (1992) $247-255$.

[25] S. Ljubojević, D. Pamučar, D. Jovanović and V. Vešović, Outsourcing transport service: a fuzzy multi-criteria methodology for provider selection based on comparison of the real and ideal parameters of providers. Oper. Res. (2017) 1-35.

[26] J.C. López, P.A.Á. Carrillo, D.A.G. Chavira and J.J.S. Noriega, A web-based group decision support system for multicriteria ranking problems. Oper. Res. 17 (2017) 499-534.

[27] M.N. Mokhtarian and A. Hadi-Vencheh, A new fuzzy TOPSIS method based on left and right scores: an application for determining an industrial zone for dairy products factory. Appl. Soft Comp. 12 (2012) 2496-2505.

[28] M. Naili, A. Boubetra, A. Tari, Y. Bouguezza and A. Achroufene, Brain-inspired method for solving fuzzy multi-criteria decision making problems (BIFMCDM). Expert Syst. Appl. 42 (2015) 2173-2183. 
[29] H.S. Najafi and S.A. Edalatpanah, A note on "A new method for solving fully fuzzy linear programming problems". Appl. Math. Model. 37 (2013) 7865-7867.

[30] S. Niroomand, A. Mahmoodirad, A. Heydari, F. Kardani and A. Hadi-Vencheh, An extension principle based solution approach for shortest path problem with fuzzy arc lengths. Oper. Res. 17 (2017) 395-411.

[31] S. Niroomand, N. Mirzaei and A. Hadi-Vencheh, A simple mathematical programming model for countries' credit ranking problem. Int. J. Finance Econ. 24 (2019) 449-460.

[32] E.Y. Peraei, H.R. Maleki and M. Mashinchi, A method for solving a fuzzy linear programming. K. J. Comp. Appl. Math. 8 (2001) 347-356.

[33] A. Ruiz-Padillo, D.P. Ruiz, A.J. Torija and Á. Ramos-Ridao, Selection of suitable alternatives to reduce the environmental impact of road traffic noise using a fuzzy multi-criteria decision model. Envir. Impact Asse. Rev. 61 (2016) 8-18.

[34] S.A. Sadabadi, A. Hadi-Vencheh, A. Jamshidi and M. Jalali, A new index for TOPSIS based on relative distance to best and worst points. Int. J. Info. Tech. Decis. Making 19 (2020) 695-719.

[35] M. Tavana, M. Keramatpour, F.J. Santos-Arteaga and E. Ghorbaniane, A fuzzy hybrid project portfolio selection method using data envelopment analysis, TOPSIS and integer programming. Expert Syst. Appl. 42 (2015) 8432-8444.

[36] Y.M. Wang and T. Elhag, Fuzzy TOPSIS method based on alpha level sets with an application to bridge risk assessment. Expert Sys Appl. 31 (2006) 309-319.

[37] J.J. Wang, Y.Y. Jing, C.F. Zhang, G.H. Shi and X.T. Zhang, A fuzzy multi-criteria decision-making model for trigeneration system. Ener. Poli. 36 (2008) 3823-3832.

[38] P. Wanke, M.A.K. Azad, C.P. Barros and A. Hadi-Vencheh, Predicting performance in ASEAN banks: an integrated fuzzy MCDM-neural network approach. Expert Syst. 33 (2016) 213-229.

[39] G. Wei, F.E. Alsaadi, T. Hayat and A. Alsaedi, A linear assignment method for multiple criteria decision analysis with hesitant fuzzy sets based on fuzzy measure. Int. J. Fuzzy Syst. 19 (2017) 607-614.

[40] B. Yatsalo, A. Korobov and L. Martínez, Fuzzy multi-criteria acceptability analysis: a new approach to multi-criteria decision analysis under fuzzy environment. Expert Syst. Appl. 84 (2017) 262-271.

[41] D. Yong and L. Qi, A TOPSIS-based centroid-index ranking method of fuzzy numbers and its application in decisionmaking. Cybern. Syst. 36 (2007) 581-595.

[42] A. Yücel and A.F. Güneri, A weighted additive fuzzy programming approach for multi-criteria supplier selection. Expert Syst. Appl. 38 (2011) 6281-6286.

[43] L.A. Zadeh, Fuzzy sets. Inf. Cont. 8 (1965) 338-353. 